\title{
A Participatory GIS Solution for Watershed Rehabilitation Project Management in the Changjiang and Pearl River Basins
}

\author{
Aihong Song / LIESMARS, Wuhan University, \\ Wuhan, China \\ songaihong@geostar.com.cn
}

\author{
Jian Liu / Wuda Geoinformatics Co., Ltd. \\ Wuhan, China \\ tony.liu@geostar.com.cn
}

\author{
Stephen C. McClure / LIESMARS, Wuhan University, \\ Wuhan, China \\ smccwst@gmail.com
}

\begin{abstract}
The Changjing and Pearl River Watershed Rehabilitation Project (CPRWRP) is typical of large-scale development projects around the world. The dual objectives of this project were specifically to mitigate soil erosion as well as to achieve livelihood improvement in degraded areas across four contiguous provinces in China. But, management and oversight of these kinds of undertakings present massive challenges for all stakeholders. To support effective, timely, and inclusive engagement among participants in the CPRWRP, an innovative Participatory Geographic Information System (PGIS) was developed and realized. It provides an interactive Web Mapping Service (WMS) to enter and visualize data in real time, and supplies online analysis and compliance tools to achieve project mission goals and sustainability objectives. User-friendly graphic and cartographic representations enhance transparency and facilitate decision making at all levels. This PGIS approach to technical problems with human dimensions is replicable, scalable and extendable to other similar sustainable development projects worldwide.
\end{abstract}

Index Terms - Participatory GIS, PGIS, MIS, Environment, Sustainable Development, Watershed Rehabilitation, Changjiang River, Pearl River, River Basin Management, Watershed Management

\section{INTRODUCTION}

Technology solves problems in the real world in real institutional contexts. This article outlines a case study of one such real world technical solution facilitating successful implementation of a large scale watershed restoration project across four contiguous provinces (Fig. 1) in China.

The aims of this watershed restoration project were twofold; to mitigate erosion and environmental degradation in the countryside while improving local people`s livelihoods. The Wuda Geoinformatics Co., Ltd. (GeoStar) in collaboration with Wuhan Changyuan Co., Ltd. (Changyuan) developed technical solutions enabling the project to be managed effectively and transparently in a participatory manner.

Soil erosion is a major environmental problem not only in China but world-wide ${ }^{[1]}$, and a critical concern for sustainable development in terms of food security, water scarcity, and flood control. The World Bank and EU in September 2006 co-financed a watershed rehabilitation project in the four Chinese provinces of Yunnan, Guizhou, Hubei and Chongqing including 37 counties - The Changjiang and Pearl River Watershed Rehabilitation Project (CPRWRP).

Implementing such a watershed restoration project is a long term commitment, involving actors at several levels of governance. Stakeholders from multiple sectors including governments, international organizations, and the farmers themselves all have an interest in both project implementation and potential outcomes. Managing and overseeing such a project presents serious challenges.

Traditionally, implementation and monitoring of large-scale development projects involve lengthy reports, massive data tables, and a large field staff, creating many opportunities for errors. These programs are often inefficient, and suffer from a lack of transparency with little civic participation. There are however, solutions that facilitate development goals, empower end users, and enable project managers and funders to oversee effectively the progress toward implementation.

In the case study described in this article, the challenges of implementing the CPRWRP were overcome by developing useroriented applications and a Web Mapping Service (WMS). The system developed by the GeoStar and Changyuan companies include a web-based Management Information System (MIS), a WMS, and a mobile field checking system with graphic interfaces engineered to fulfill the needs of project stakeholders including central, provincial, and county administrators.

The system builds upon and extends the research concerning GIS technologies, decision support, and Participatory GIS (PGIS). Policy support systems based on GIS are one tool for sustainable development available to decision makers ${ }^{[2]}$. Such systems provide valuable information to stakeholders managing natural resources on a global ${ }^{[3]}$, regional ${ }^{[4]}$ or local scale ${ }^{[5,6,7]}$. These systems are quickly evolving in tandem with the rapid development of the Internet, especially with the proliferation of Cloud Computing technologies ${ }^{[8]}$. Migrating standalone applications to online applications and WMSs for visualization are growing trends. In recent years, participatory GIS applications and approaches have also gained increasing attention for land use management and decision making ${ }^{[9]}$. Research has focused on the developing ways to incorporate mixed media and 
local knowledge in a GIS as well as web based collaborative decision support tools that promote greater transparency ${ }^{[10,11]}$

The case study described in this article extends this research by developing a working system appropriate for project management and oversight; it contributes to both a solution to the soil erosion problem in China and the work on PGIS.

The rest of this article will be as follows: Section II includes a description of the CPRWRP, section III describes the GIS platform, section IV details the mobile checking system, section $\mathrm{V}$ discusses the MIS, ending with brief conclusions in Section VI.

\section{THE CPRWRP PROJECT}

The CPRWRP started late 2006 and was completed in mid2012. Four continuous provinces participated in this project; the project area comprised 180 mountainous or hilly sub-watersheds in 37 counties in Yunnan, Guizhou, Chongqing, and Hubei provinces. Within the two major river basins, critical areas were identified from remotely sensed imagery and scientific analysis.

A World Bank (WB) loan of 100 million US dollars, a European Union (EU) grant of 10 million Euros and a Government of China (PRC) contribution of 88 million US dollars financed the project. In addition the EU-China River Basin Management Program (RBMP), also funded by the EU, provided technical assistance for the project including financing of capacity building at all levels of the project organization

On abandoned slopes in the target area, the project implemented a range of environmental and soil conservation measures such as afforestation, closure of severely degraded areas for natural regeneration of vegetation, and construction of diversion drains and check dams to stop gully erosion.

Linked to these environmental measures were livelihood improvement measures, co-financed by farmers by undertaking loans and providing labor to establish orchards, make livestock purchases, and construct stables and water tanks for irrigation and drinking water supply,

Four main principles guided project planning and implementation:

1. Integration of soil and water conservation and livelihood improvement measures

2. A participatory approach involving beneficiary households in identification, decision-making, planning and implementation of project activities

3. Low-interest loans to enable farmers to invest in changing to more sustainable, environmentally friendly and productive farming systems

4. Small grants from the EU enabling poor, ethnic minority and female-headed households to participate in the project

The project had dual objectives:

1. To reduce soil erosion and conserve water

2. To improve the livelihoods and income of the rural population.
To achieve these objectives, the project encouraged and supported farmers to give up cultivation and open grazing on steep mountainous slopes and instead take up sustainable and higher income farming systems.

A Central Project Implementation Office (CPIO), based in the Changjiang Water Resources Commission in Wuhan, coordinated the project. At the provincial level, the project was administered by Provincial Project Management Offices (PPMOs), while County PMO's (CPMOs) managed the subwatershed implementation in collaboration with Township administrators and technicians, Village Committees, and farmers.

During project design it became clear that a Management Information System (MIS) would be required to keep track of the enormous amount of data generated through planning, implementation, checking, acceptance, payment and reimbursement of the project measures and funding. The original design included some 20 measures with different rates of subsidies, to be implemented in 274 sub-watersheds, each with different packages of measures, distributed across 37 counties in 4 provinces, each with different budgets.

During implementation, the MIS evolved from a top-down administrative tool, increasing the workload of the lowest levels of management and benefiting only the central project management, to a bottom-up tool benefiting all levels of project management.

\section{THE GIS PLATFORM}

GeoStar created a map based interface to make the MIS userfriendly for project managers as well as external stakeholders not involved in day-to-day management of the project. The map based interface includes functionalities such as on-line access to the MIS database via the Internet from office based desktop computers or from mobile computing platforms such as tablet devices and smart-phones. The latter enabled a mobile GPSbased checking system, including accurate location of subwatershed maps and an application to record short geo-referenced notes and photographs of any good, incomplete or unsatisfactory work observed during field checking.

The interface (Fig. 1) applies an intuitive map-based navigation tool enabling users to zoom from the entire project area to individual sub-watershed maps or even individual plots. At each level, a set of pre-defined key data on project status is provided and for some data, implementation progress over time can be displayed, all of which enables users to readily identify implementation bottlenecks. The system is dynamic in that the graphs at all times reflect the most recent data entered into the MIS database.

The top menu (Fig. 1) also includes analysis of year-on-year progress in implementation of selected measures by provinces. Since project implementation extended over six years, line graphs revealed periods of fast and slow implementation as well as apparent data entry errors. The analytical tool showed that the restructuring of the CPRWRP, which seriously slowed down 
most project activities during 2008 and 2009, did not affect implementation of measures that were locally in high demand, such as orchard establishment in Hubei and stonewall terraces in Guizhou.

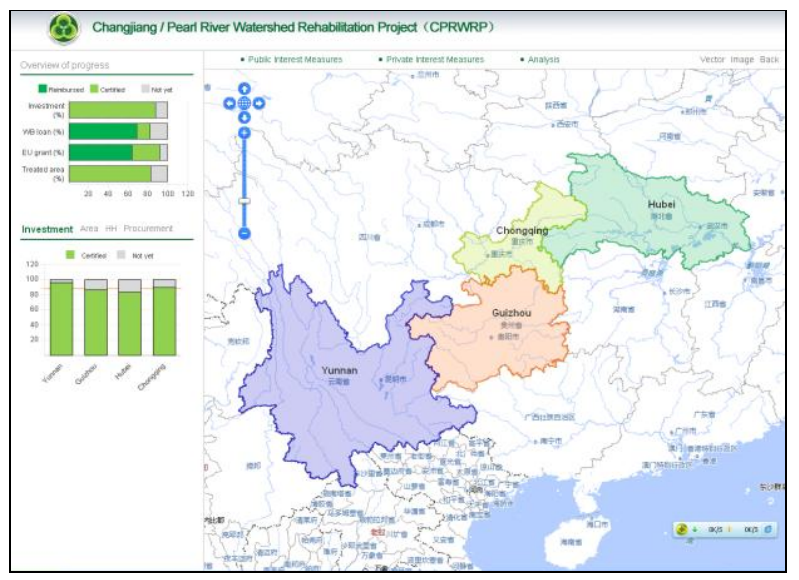

Figure 1 The system interface shows the project target areas

\section{THE MOBILE CHECKING SYSTEM}

The interface is accessible via the Internet from office desktops and also via mobile smart-phones or tablets, thus making it possible to carry out on-site field checks (Fig. 2). The interface may be considered as a proto-type of web portals giving the public access to meta-data on environmental projects. Access to sub-watershed project maps via mobile smart-phones makes it possible to carry out on-site field checks and take geo-referenced field notes and photos, thus facilitating and documenting checking, reporting of issues and acceptance of individual project measures

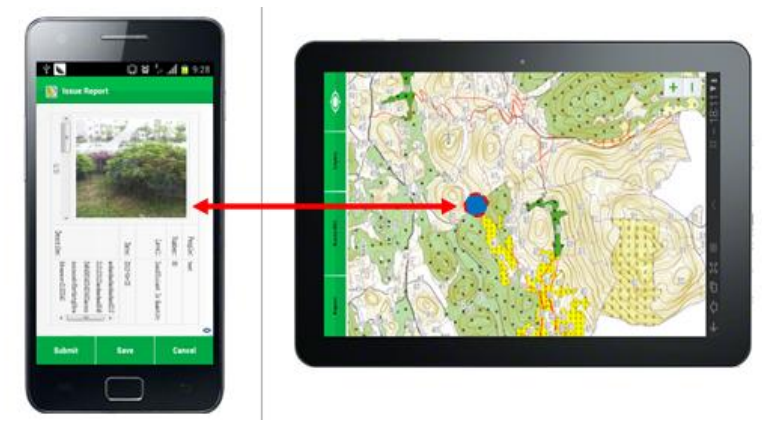

Figure 2 The mobile system for smart-phones and tablets

\section{THE MIS SYSTEM}

The main purpose of the MIS was to provide information for provincial and central project monitoring, but it provided no immediate benefits to the CPMO staff. On the contrary, it required the CPMO staff to manually large amounts of data, which already had been entered in spreadsheets for preparation of preliminary sub-watershed design reports. Data entry into the MIS proved to be exceedingly slow, because it had to take place on-line and at the start of the project, the Internet connection of many CPMO offices in remote areas was both slow and unstable. This resulted in frequent system crashes and loss of data. As a result, CPMO staff became increasingly reluctant to enter their data and the system fell into disuse.

In 2007, when Technical Assistance Team of the EU-China RBMP was mobilized, the performance of the MIS was reviewed and the main deficiencies and bottlenecks were identified in consultation with the county staff responsible for data entry. The recommended changes were implemented in early 2008 including new features such as batch input of data directly from existing spreadsheets, off-line submission of data and a hotline for on-line or telephone support.

During restructuring of the CPRWRP in 2009, the number of sub-watersheds was reduced to 180 , but unit prices and subsidies were adjusted adding further complexity to project management. That year, the RBMP team and the CPIO completed the Participatory Design Manual (PDM), which contains clear guidelines for sub-watershed planning and design.

The restructured MIS (Fig. 3) was built in five stages reflecting the iterative, solution oriented approach:

1 A county level Design Tool for data entry and output of county level sub-watershed planning reports, subsequently upgraded to a full county level management module

2 A central database for uploading and aggregation of county level baseline, design and progress data

3 A web-based query and reporting interface accessing the database and able to generate documentation for project planning, monitoring and management at all levels of the project

4 A map-based interface providing Internet access to a set of predefined key data at project, province, county and subwatershed levels from office computers and mobile phones

5 A mobile application for on-site recording of georeferenced notes and photos during monitoring, checking, acceptance and supervision missions.

In consultation with the CPMO staff on their requirements for a Sub-Watershed Design Tool, the team then developed a decentralized, desktop-based Design Tool, which standardized data entry and computerized generation of all tables for the subwatershed design reports, household transparency cards, loan agreements and other documentation. The Design Tool was at first received reluctantly by the CPMO staff, but this changed quickly, when they experienced the workload reduction made possible by the tool.

A rough estimate is that for each sub-watershed the CPMO staff saved 30-40 working days by computerized generation of transparency cards and loan agreements, a task that previously took 10-15 minutes per household to fill in by hand. For the 
entire project this amounted to at least 5,000 working days or 20 person-years. Ideally, this time was used for more productive work.

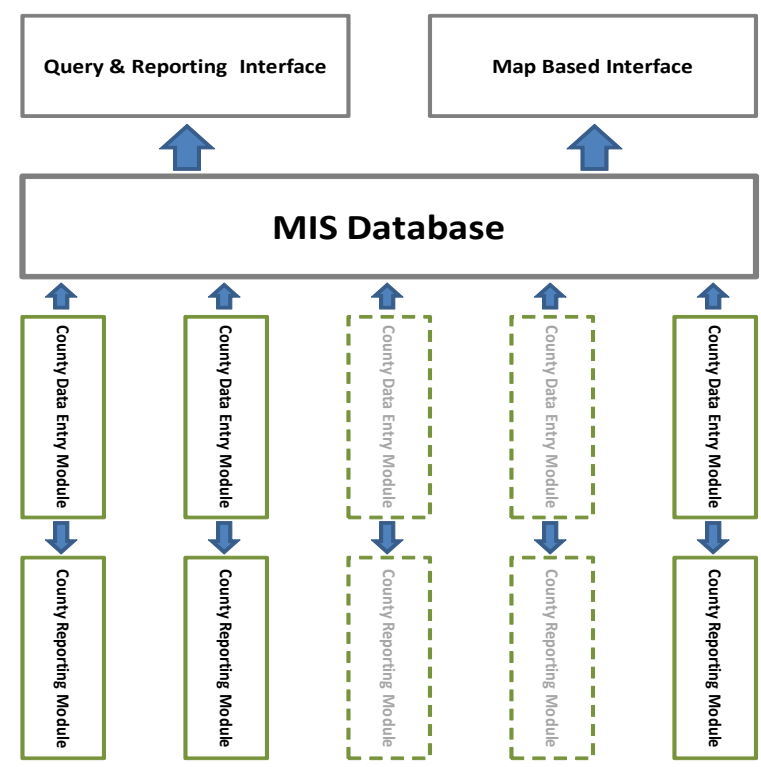

Figure 3 The MIS structure

\section{CONCLUSIONS}

Large scale environmental projects like the CPRWRP require a participatory approach, involving stakeholders at all levels for effectiveness and transparency. These types of projects are complex with many challenges both institutional and technical. The CPRWRP case study reported in this article demonstrates how multiple technologies were integrated to meet those challenges. A desktop design tool, a web-based MIS, a WMS and a Mobile Checking system were developed to satisfy management and oversight requirements at different levels. Most importantly, the system significantly reduced staff workloads so that people, their livelihoods, and sustainable development rather than administrative tasks were the primary focus of project agencies, managers and field engineers.

The resulting system saved CPRWRP staff more than 5,000 working days, provided direct access to detailed project information for all key stakeholders, and enabled an unprecedented level of transparency at all levels of the project from participating households to EU and World Bank managers.

A practical and robust solution for project management and implementation issues was conceived, designed and realized in the process of addressing soil erosion and watershed restoration in an iterative participatory manner. Smart systems including ground-based sensor networks, human networks, satellites and other decision support and visualization tools will be incorporated into future applications. As described in this article, this PGIS approach to technical problems with human dimensions is replicable, scalable and extendable to other similar sustainable development projects worldwide.

\section{ACKNOWLEDGMENT}

Many thanks to CPRWRP stakeholders including the CPIO, provincial and county PMO staff, and special thanks to the EU technical assistance team experts: Mr. Lars Skov Andersen and Dr. Piet van der Poel.

\section{REFERENCES}

[1] D. Pimentel. "Soil erosion: a food and environmental threat," Environment, Development and Sustainablity, vol. 8, pp. 119-137, 2006.

[2] S. J. Ventura. "The use of geographic information systems in local government," Public Administration Review, vol. 55(5), pp. 461467, September 1995.

[3] T. Guoxin, R. Shibasaki, and K. Matsumura. "Development of a GIS-based decision support system for assessing land use status," Geo-spatial Information Science, vol. 7, pp. 72-78, March 2004.

[4] D. Lane, W. Michalowski, R. Stephenson, and F. Page. "Integrated systems analysis for marine site evaluations and multicriteria decision support for coastal aquaculture," In Aquaculture, Innovation and Social Transformation, pp. 255-264, 2009.

[5] J. Coutinho-Rodrigues, A. Simão, and C. H. Antunes. "A GISbased multicriteria spatial decision support system for planning urban infrastructures," Decision Support Systems, vol. 51(3), pp. 720-726, June 2011.

[6] M. R. Thomas. "A GIS-based decision support system for brownfield redevelopment," Landscape and Urban Planning, vol. 58(1), pp. 1-18, 2002.

[7] W. O. Ochola and P. Kerkides. "A spatial decision support system for water resources hazard assessment: local level water resources management with GIS in Kenya," Journal of Geographic Information and Decision Analysis, vol. 7(1), pp. 32-46, 2003.

[8] C. Yang, R. Raskin, M. Goodchild, and M. Gahegan. "Geospatial cyberinfrastructure: past, present and future," Computers, Environment and Urban Systems, vol. 34(4), pp. 264-277, 2010.

[9] S. Carver, A. Evans, R. Kingston, and I. Turton. "Public participation, GIS, and cyberdemocracy: evaluating on-line spatial decision support systems," Environment and Planning B: Planning and Design, vol. 28, pp. 907-921, 2001.

[10] P. A. K. Kyem. "Exploring conceptual issues between public participation GIS (PPGIS) and conventional GIS practice," paper presented to the Annual Conference of the American Association of Geographers, Pittsburgh, PA, 4-8 April 2000, http://www.uky.edu/AS/Geography/faculty/harvey/html/pykem.ht $\mathrm{m}$, last accessed May 2, 2012.

[11] S. S. Han, Z. Peng. "Public participation GIS (PPGIS) for town council management in Singapore," Environment and Planning B: Planning and Design, vol. 30(1), pp. 89 - 111, 2003. 